\title{
Room for Improvement in the Use of High-Quality Preschool Programs for California's Children
}

RAND RESEARCH AREAS

THE ARTS

CHILD POLICY

CIVIL JUSTICE

EDUCATION

ENERGY AND ENVIRONMENT HEALTH AND HEALTH CARE INTERNATIONAL AFFAIRS NATIONAL SECURITY POPULATION AND AGING PUBLIC SAFETY SCIENCE AND TECHNOLOGY SUBSTANCE ABUSE TERRORISM AND HOMELAND SECURITY TRANSPORTATION AND INFRASTRUCTURE

This product is part of the RAND Corporation research brief series. RAND research briefs present policy-oriented summaries of published, peer-reviewed documents.

Corporate Headquarters 1776 Main Street P.O. Box 2138

Santa Monica, California 90407-2138

TEL 310.393 .0411

FAX 310.393 .4818

(c) RAND 2008
C

alifornia has fallen behind on many key indicators of education performance, prompting policymakers to look for strategies to improve student outcomes. Among the policy options being considered is the possibility of expanding public funding for preschool education as part of a broader agenda of education reform. To provide a foundation for evaluating the potential of such an expansion and how best to implement it, the RAND Corporation is undertaking the California Preschool Study, which seeks a better understanding of

- the size of achievement shortfalls overall in the early elementary grades and gaps in school performance between groupsdefined, for example, by race-ethnicity or socioeconomic status - and the potential for preschool education to close existing gaps

- how publicly funded early care and education (ECE) programs are structured and how effectively ECE funds are being spent

- rates of access to high-quality early learning programs among California’s children.

The last issue is addressed by the third study report, which is summarized in this brief. The purpose of the study has been to establish the extent to which there is room for improvement in preschool access or program quality and whether some groups of children are particularly underserved. Until now, the information necessary to make these characterizations for preschool-age children in California has been unavailable.

\section{New Data to Fill the Knowledge Gap}

The RAND study drew a representative sample of California children of preschool age. In the first half of 2007, a household survey collected information for just over 2,000 children eligible to enter kindergarten in the fall of 2007 or 2008. For convenience, this brief refers to these chil-

\section{Key findings:}

- Use of center-based early care and education (ECE) is the norm for California families with three- and four-year-olds, although socioeconomically disadvantaged children participate at lower rates.

- These programs fall short on some quality benchmarks, particularly those for the promotion of thinking and language skills.

- All groups of children in center-based ECE experience quality shorffalls.

- The groups of children with the largest gaps in school readiness and later school achievement are the least likely to participate in high-quality center-based ECE programs that will help them succeed in kindergarten and beyond.

- There is plenty of room for improving the quality of preschool for all children-and for raising preschool-participation rates for children who could benefit the most.

dren, respectively and somewhat loosely, as fouryear-olds and three-year-olds.

The household interview, conducted with the sampled child's parent or guardian, obtained information on the regular ECE arrangements for the child, including center-based early learning or child-care programs, as well as home-based care provided by a relative or nonrelative. To obtain further information about the children's ECE setting, the researchers conducted about 700 telephone interviews with ECE-provider personnel, which, for children in center-based programs, were the program director and the child's lead classroom teacher or caregiver. 
Finally, to obtain objective information on the quality of ECE arrangements in center-based programs, specially trained observers collected well-validated measures of multiple dimensions of ECE quality for about 250 programs in the provider sample. In addition to structural measures, such as group sizes, child-staff ratios, and teacher qualifications, the measures included two nationally recognized tools: the Early Childhood Environment Rating Scale, revised edition (ECERS-R), and the Classroom Assessment Scoring System (CLASS). The latter two comprehensive assessments of ECE quality have been linked to child-development outcomes and later school performance.

The remainder of this brief highlights the study's key findings, first for the use of center-based ECE arrangements, and second for the quality of center-based ECE programs. It concludes by summarizing implications of the findings for early education policy in California.

\section{Participation in Center-Based ECE Programs Is the Norm, Especially for Four-Year-Olds}

An estimated 59 percent of preschool-age children in California are in public or private center-based ECE programs. That includes two-thirds of four-year-olds and just over half of three-year-olds. The center-based settings represent a mixture of public and private programs. Twenty-two percent of preschool-age children are in a publicly funded program, such as Head Start or a state, county, or school-district program, and 27 percent are in a private-school prekindergarten or a preschool or nursery school. Nine percent are in a center less focused on early education. The remaining children either receive care only from their parents ( 25 percent) or have a relative or nonrelative providing care in a home-based setting as the only regular source of care by someone other than their parents (16 percent).

\section{Disadvantaged Children Participate in Center-Based ECE at Lower Rates}

The RAND researchers found that use of center-based ECE programs varied with different demographic and socioeconomic factors. Various socioeconomic status measures are strongly associated with ECE use (see Figure 1 for use of center-based programs). The general pattern is that ECE use rises with socioeconomic status. For example, just 45 percent of children whose mothers have less than a high-school diploma are in center-based ECE, compared with 80 percent of those whose mother has a graduate degree.

Use of center-based ECE also generally rises with family income. There may be an exception for families with income just above poverty level, for whom the use of center-based ECE is relatively low. In this range, families may earn too much for their children to receive priority in placement in
Figure 1

Use of Center-Based ECE Is Lowest for Socioeconomically Disadvantaged Groups

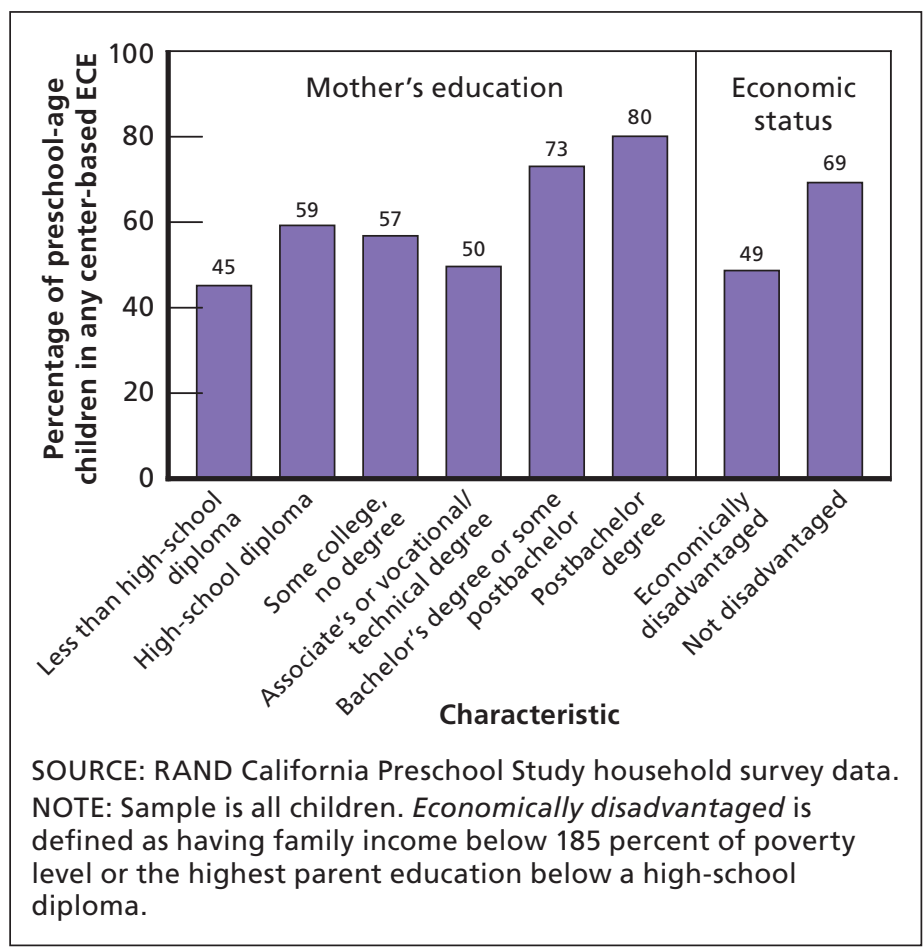

publicly subsidized programs (for which more children are eligible than there are funded spaces), but they may not earn enough to afford other ECE arrangements.

There are also differences in participation rates along racial-ethnic lines, with the lowest rates of use by Latino children. However, the gap between Latinos and the other groups narrows when family income and maternal education are controlled for. Thus, for children who differ racially or ethnically but are similar in terms of socioeconomic status and other factors, there are smaller differences in participation.

\section{Quality Is Mixed in Center-Based Programs}

In keeping with the child-development literature, the research team treated quality in center-based programs as having multiple dimensions. Based largely on the classroom observations, the researchers found that the quality of center-based settings in California varies with the measure examined (see Figure 2). Programs were more successful in meeting quality benchmarks for group sizes and ratios and scored higher on measures of the classroom environment that focus on emotional support, classroom management, and student engagement. The largest shortfall occurs on the extent to which teachers promote language development and the higher-order thinking skills that help prepare children for kindergarten. Other aspects of quality with room for improvement are teacher edu- 
cation and training, the use of research-based curricula, and basic health and safety measures.

\section{Group Sizes and Ratios}

Typical benchmarks for high-quality programs serving preschool-age children specify a maximum group size of 20 and a maximum child-staff ratio of 10 to 1 . Based on the study team's observations, 71 percent of children in centerbased programs are in classrooms that would meet the benchmark of 20. Seventy-seven percent of children are in classrooms that would meet the benchmark of 10 to 1 .

\section{Teacher Education and Training}

There is no consensus in the early childhood field regarding the education and training requirements for ECE teachers to be effective, although more education and training in the ECE field are typically associated with higher quality and have been linked to better child-development outcomes. Even though California has no degree requirement for lead teachers in center-based programs, two-thirds of children in such programs have a lead teacher with at least an associate's degree. In contrast, a benchmark specifying a bachelor's degree in the ECE field would be met for just over onequarter of children in center-based programs.

\section{Figure 2}

Quality in Center-Based Programs Is Lowest for Measures Linked to Early Learning

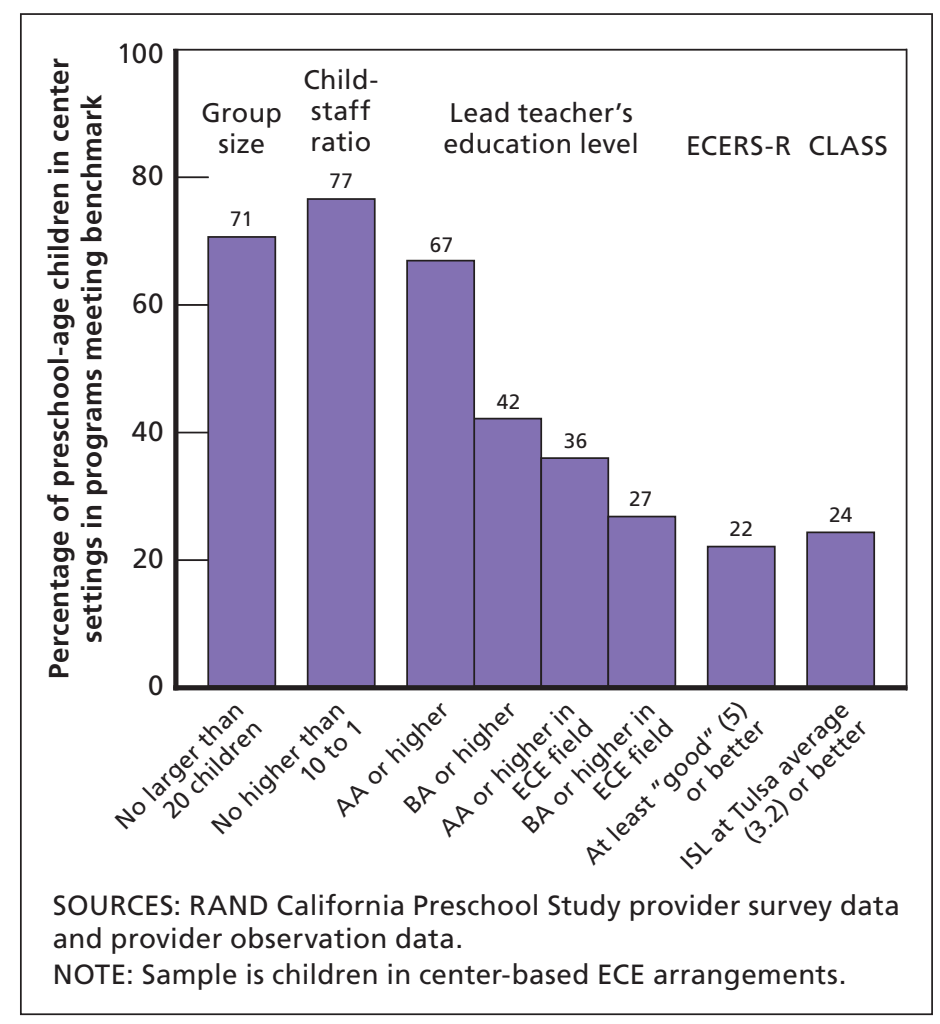

\section{Classroom Environment and Interactions}

Using a scale of 1 (inadequate) to 7 (excellent), trained observers from the RAND team scored ECERS-R subscales for space and furnishings and for activities. The combined score across the two subscales was just greater than 4, on average, for children in center-based programs, a result between minimally acceptable (a score of 3 ) and good (a score of 5). Only 22 percent of children in center-based programs are in classrooms with a combined ECERS-R score of at least 5 .

The trained observers also scored the CLASS assessment, which is divided into four domains. Preschool-age children in center-based programs are, on average, in classrooms with a score close to or just above 5 (again, on a 1-to-7 scale) on three of the CLASS domains-emotional support, classroom organization, and student engagement. The big shortcoming is in the fourth domain-instructional support for learning (ISL), for which the mean score is 2.6. This domain is important because it includes promotion of language skills and higher-order thinking and is strongly predictive of gains on cognitive assessments and subsequent student-achievement tests. Only one in four preschool-age children in California in a center-based program is in a classroom with an ISL score of at least 3.2-the average for Tulsa classrooms in Oklahoma's universal preschool program, which has been shown to improve school readiness.

\section{All Groups of Children Experience Low Quality}

Among children in center-based ECE, demographic and economic characteristics of children are generally not associated with large differences in program quality. The differences in quality are most evident, but still modest, for children classified by race-ethnicity and by household income. African American children tend to be in programs with lower quality measures, while whites see higher quality. Scores on the ECERS-R and CLASS quality scales tend to rise with income-but children with incomes below poverty have the best-educated teachers.

Notably, some dimensions of quality are highest for public preschool programs. Children in such programs as California State Preschool and public prekindergarten are more likely to reach some quality benchmarks. For example, almost half of the children in such programs have lead teachers with a bachelor's degree or higher in the ECE field, compared with about one in eight children in private-school prekindergartens or in child-care centers.

However, all groups of children in center-based programs, regardless of where they go, are in programs falling short on key quality benchmarks. Even for those racial and income groups in the highest-quality programs, the average ECERS-R score falls below good, and the CLASS ISL score falls short of the Tulsa average. 


\section{Implications for Early Education Policy in California}

While a comprehensive analysis of policy options and recommendations will be undertaken as part of the final report of the RAND California Preschool Study, this brief highlights here three implications that readily follow from the current findings.

\section{Participation in High-Quality Center-Based Programs Is Lowest for Groups of Children Who Could Benefit the Most} Earlier work in this study found lower measures of school readiness and subsequent academic performance among Latinos and African Americans, children whose parents have low education, and those from economically disadvantaged families. The current analysis shows that these same groups are the least likely to be in center-based ECE programs that meet quality benchmarks. Based on such measures as group size, ratios, and teacher education, 20 to 50 percent of children in these groups are in a center-based program that meets benchmarks for quality in these domains. For quality measures that are linked to school performance, such as the CLASS ISL, at best 15 percent of children who could benefit the most from a high-quality early learning experience are in such programs. These low participation rates in high-quality programs represent a missed opportunity to promote the cognitive and social development of more disadvantaged children.

\section{There Is Room to Expand Use by Underserved Groups and to Raise Quality Across the Board}

The low rates of participation in high-quality ECE programs among those with gaps in school readiness and later school achievement reflect their overall low rates of use of any center-based programs, regardless of quality. While low participation rates are an issue for targeted populations, the need to raise program quality is universal, especially on such measures as the CLASS ISL. Despite the challenge, the CLASS scores that have been measured for the publicly subsidized centers evaluated as part of the Preschool for All (PFA) initiatives in San Francisco and San Mateo counties-exceeding even those measured for Tulsa's highperforming program-provide encouragement that higher quality can be achieved. The PFA initiatives emphasize program quality and include higher rates of reimbursement for centers that achieve quality benchmarks.

\section{Quality Initiatives Need to Focus on Elements That Are Key to Kindergarten Readiness}

The team's estimates indicate that a substantial percentage of preschool-age children are in center-based programs that would meet well-established benchmarks for group size and ratios. Building on that foundation requires advances in other areas, in which quality levels are not as high. Training and professional-development opportunities could provide teachers with the tools to succeed at the challenging aspects of early education that are key for promoting success in kindergarten and beyond, such as fostering language skills and higher-order thinking.

The study summarized in this research brief was based on original survey and observation data collected from California families and ECE providers by the RAND research team in 2007. The California Governor's Committee on Education Excellence, the California State Superintendent of Public Instruction, the Speaker of the California State Assembly, and the President pro Tempore of the California State Senate requested the RAND California Preschool Study. The David and Lucile Packard Foundation, W. K. Kellogg Foundation, The Pew Charitable Trusts through the National Institute for Early Education Research, The W. Clement and Jessie V. Stone Foundation, and Los Angeles Universal Preschool provided funding. The project has been guided by an advisory group of academic researchers, policy experts, and practitioners.

Two companion reports and associated research briefs are also available:

- Who Is Ahead and Who Is Behind? Gaps in School Readiness and Student Achievement in the Early Grades for California's Children, by Jill S. Cannon and Lynn A. Karoly, TR-537-PF/WKKF/PEW/NIEER/WCJVSF/LAUP, 2007, available at http://www.rand.org/pubs/technical_reports/TR537/

- The Promise of Preschool for Narrowing Readiness and Achievement Gaps Among California Children, RB-9306-PF/WKKF/PEW/NIEER/WCJVSF/LAUP, 2007, available at http://www.rand.org/pubs/research_briefs/RB9306/

- Early Care and Education in the Golden State: Publicly Funded Programs Serving California's Preschool-Age Children, by Lynn A. Karoly, Elaine Reardon, and Michelle Cho, TR-538-PF/WKKF/PEW/NIEER/WCJVSF/LAUP, 2007, available at http://www.rand.org/pubs/technical_reports/TR538/

- Publicly Funded Early Care and Education Programs for California Preschool-Age Children, RB-9307-PF/WKKF/PEW/NIEER/WCJVSF/LAUP, 2007, available at http:// www.rand.org/pubs/research_briefs/RB9307/.

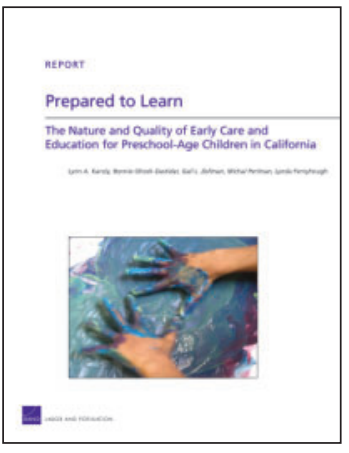

This research brief describes work done for RAND Labor and Population and documented in Prepared to Learn: The Nature and Quality of Early Care and Education for Preschool-Age Children in California, by Lynn A. Karoly, Bonnie Ghosh-Dastidar, Gail L. Zellman, Michal Perlman, and Lynda Fernyhough, TR-539-PF/WKKF/PEW/NIEER/WCJVSF/LAUP, 2008, 250 pp., available at http://www.rand.org/pubs/technical_reports/TR539/. The RAND Corporation is a nonprofit research organization providing objective analysis and effective solutions that address the challenges facing the public and private sectors around the world. RAND's publications do not necessarily reflect the opinions of its research clients and sponsors. RAND ${ }^{\circledR}$ is a registered trademark.

RAND Offices

Santa Monica, CA • Washington, DC • Pittsburgh, PA • Jackson, MS/New Orleans, LA • Doha, QA • Cambridge, UK • Brussels, BE 


\section{RAND LABOR AND POPULATION}

THE ARTS

CHILD POLICY

CIVIL JUSTICE

EDUCATION

ENERGY AND ENVIRONMENT

HEALTH AND HEALTH CARE

INTERNATIONAL AFFAIRS

NATIONAL SECURITY

POPULATION AND AGING

PUBLIC SAFETY

SCIENCE AND TECHNOLOGY

SUBSTANCE ABUSE

TERRORISM AND HOMELAND SECURITY

TRANSPORTATION AND

INFRASTRUCTURE

WORKFORCE AND WORKPLACE
This PDF document was made available from www.rand.org as a public service of the RAND Corporation.

This product is part of the RAND Corporation research brief series. RAND research briefs present policy-oriented summaries of individual published, peerreviewed documents or of a body of published work.

The RAND Corporation is a nonprofit research organization providing objective analysis and effective solutions that address the challenges facing the public and private sectors around the world.

\section{Support RAND}

$\underline{\text { Browse Books \& Publications }}$

Make a charitable contribution

\section{For More Information}

\author{
Visit RAND at www.rand.org \\ Explore RAND Labor and Population \\ View $\underline{\text { document details }}$
}

Limited Electronic Distribution Rights

This document and trademark(s) contained herein are protected by law as indicated in a notice appearing later in this work. This electronic representation of RAND intellectual property is provided for non-commercial use only. Unauthorized posting of RAND PDFs to a non-RAND Web site is prohibited. RAND PDFs are protected under copyright law. Permission is required from RAND to reproduce, or reuse in another form, any of our research documents for commercial use. For information on reprint and linking permissions, please see RAND Permissions. 